\title{
Contextualized Grammar in EFL Students' Writings: A Case for Corrective Feedback
}

\section{Ayman Sha'ban Khalifa Ahmad}

Assistant Lecturer of Curriculum and Instruction (TEFL), Faculty of Education (Cairo) - Al-Azhar University.

\section{Attia Abdul Kader Al-Tanany}

Professor of Curriculum and Instruction (TEFL), Faculty of

Education (Cairo), Al-Azhar University

\section{Hany Ibrahim Musa}

Associate Professor of Curriculum and Instruction (TFFL) - Faculty

of Education (Cairo) Al-Azhar University

\section{ABSTRACT}

The current study aimed at empirically
exploring the effectiveness of the direct versus
indirect modes of corrective feedback in developing grammatical accuracy in writing among the EFL majors at the Faculty of Education, Al-Azhar University. The participants of the study (totaling 50) were randomly assigned from the first year EFL students at the Faculty of Education of Al-Azhar University in Cairo and categorized into two experimental groups studying a program designed for contextualizing grammar in writing. To assess the findings of that program and fulfill the purposes of the study, a writing test and its analytic scoring rubric was developed. The results of the study consistently demonstrated that both direct and indirect modes of feedback had high effectiveness in developing grammatical accuracy in writing as the participants who received direct or indirect corrective feedback showed better performance in the post-test than that of the pre-test. The study ended with discussing the findings reached, presenting recommendations, and suggesting some issues for further research.

Keywords: writing, grammatical accuracy, corrective feedback, direct corrective feedback, indirect corrective feedback.

\section{Introduction :}

The ability to write in a foreign language is indeed at the very heart of using a foreign language because writing, 
as a productive skill, has a primary function of making thinking visible and ideas concrete. As such, it is considered to be one of the principal bases upon which learning and intellect are evaluated. It can be used to impart information, voice opinions, pose questions or disseminate pieces of literary work.

Writing in a foreign language, especially English, clearly and truthfully contributes to the success of the learner not only in the classroom but also in every sphere of life. Added to that, a good command of the writing skill enables learners to convey their messages with clarity and ease and contribute greatly in their current and future success. Subsequently, writing is skill that can no longer be neglected or superficially addressed (Han, \& Hiver, 2018).

Contrariwise, writing is characterized as being problematic, more complex and sophisticated skill. It is not merely an act of arranging graphic symbols based on certain convention to form words and sentences so as to convey the intended message. Therefore, many researchers consider writing as the most sophisticated productive skill, if compared with other language skills, which may need less effort because of the different mental activities it entails to be well performed in the final form (Özdemir, \& Aydin , 2015).

Although producing accurate writing is an essential component of the EFL learners' success in both universitylevel class and their future professional career, it is a major challenge for EFL learners. In other words, a text of an effective EFL/ESL writer must be cohesive, logical, clearly structured, interesting and properly organized with a wide range of vocabulary and mastery of grammar, conventions and mechanics (Likaj, 2015).

Another point to be considered is that writing and grammar are so intimately linked that studying one entails 
studying the other, and accurate grammatical structures are indispensable aspects of any good piece of writing. Through grammar, ideas are put into comprehensible sentences so that they can successfully and clearly convey the intended message in a written form and avoid communication misunderstanding (Fareed, et al., 2016). Furthermore, writing requires accurate in-depth knowledge of the grammar system (Myhill, \& Watson, 2014), and the writing time is considered an excellent chance to introduce some grammatical aspects in authentic learning contexts, whether the writing assignment is only a paragraph or multiple pages in length. Subsequently, grammar instruction should be contextualized in writing in order to achieve the potential positive effects of producing grammatically accurate piece of writing (Cawley, 2017).

However, achieving grammatical accuracy in writing is a complex process that necessitates "making a series of decisions about when and why to use one form rather than the other" (Celce-Murcia, 2002, p. 121). Moreover, producing a coherent, fluent and flawless piece of writing is probably a continuing challenge encountered by EFL learners in learning a foreign language (Iswandari, et al., 2017; Mahmoudi, 2017). Thus, not only is it reasonably common for EFL learners to make errors while writing, but also it is unrealistic for learners in general, and EFL in particular, to expect to reach $100 \%$ of grammatical accuracy in writing. Nonetheless, they should aim to improve continuously their grammatical accuracy in writing, in order to make their work readable, communicable and error-free (Bitchener, 2008; Ellis, 2009; Liao, 2016; Shintani, \& Aubrey, 2016).

Errors have always been of considerable interest to teachers, curriculum designers and test developers. They are natural phenomena and inextricable parcels of in 
languages. As such, it is reasonably communal for learners, in writing, to make errors and for teachers or instructors to correct such learners' errors. From this perspective, it is necessary to take into consideration that errors are inevitable in the language learning process and committing errors is an irrefutable component of learning such a language (Chu, 2011).

Krashen et al., (1982, p. 138) depicted errors as "the flawed side of learner's speech or writing". They are those parts of conversation or composition that deviate from some selected norms of mature language performance (Singh, et al., 2017). James (2013) differentiated between "errors" and "mistakes" or systematic and non-systematic errors. It was emphasized that an error takes place as a result of lack of knowledge (i.e. it indicates a gap in the learner competence) and a mistake is a performance phenomenon, reflecting processing failures that arise as a result of lack of automaticity memory lapses and physical or psychological states such as fatigue or inattention.

By the same token, with the advent of universal grammar hypothesis of Chomsky (1965), human being has been believed to have an innate capacity that can guide him through a vast number of sentence generation possibilities. As such, a shift by language teachers towards the cognitive approach has started and Chomsky's hypothesis contributed in raising researchers' interests about learners' errors as inevitable and a source of hypotheses formation (Amara, 2015).

This error inevitability motivated researchers in the field of applied linguistics and language instruction to search for feasible tools to rectify learners' errors and assist them to produce accurate written product (Phuket, \& Othman, 2015). Thereupon, corrective feedback has been suggested by many researchers to do this as it is considered 
one of the feasible solutions for the students' competence errors and a central element in improving grammatical accuracy in writing context (Sermsook, et al., 2017).

In theory, cognitivists view corrective feedback as an effective learning tool that sustains learners via providing them with sufficient information to self-control and self-regulate their own learning (Bangert-Drowns, et al., 1991). Furthermore, on the basis of cognitive theories, "corrective feedback promotes learning because it induces noticing and noticing-the gap" (Sheen, 2010, p.170).

A wealth of literature revealed that corrective feedback leads to the improvement of the learner's language. In other words, corrective feedback helps learners notice the gaps between the target language standards and their own performance; consequently, they will have the ability to reform the erroneous structures (Abbasian, \& Parsarad, 2013; Diab, 2015; Hosseiny, 2014; Kang, \& Han, 2015). It can enable learners to overcome their errors in their own writings, assist them to acquire correct English, improve their grammatical accuracy in writing at least on a long-term basis, prevent wrong structures fossilization, and upgrade their writing skills (Diab, 2016).

Ellis (2009), in his typology of corrective feedback, identified six main modes of corrective feedback, namely, direct, indirect, meta-linguistic, focused versus unfocused, reformulation and electronic corrective feedback. Such modes have been grouped into two major categories precisely, direct and indirect. The other modes can be just considered forms of how to present the corrective feedback in one of the two major modes (Shepherd, et al., 2016).

Direct corrective feedback as described by Bitchener and Knoch (2009 28) is "the provision of the correct linguistic form or structure by the teacher to the student 
above the linguistic error". Indirect corrective feedback, on the other hand, is "the indication that in some way an error has been made by underlining the errors or circling them without providing explicit comments". Although a considerable amount of research has stressed the effectiveness of the direct and indirect modes of corrective feedback, fierce debate has been presented in the annals of research concerning the superiority of a mode over the other, but there is no clear irrefutable answer for such debate (Abadikhah, \& Ashoori, 2012; Hartono, 2016; Hosseiny, 2014; li, 2013; Nakazawa, 2006; Seiffedin, \& El-Sakka, 2017, Vinagre, \& Muñoz, 2011; Vyatkina, 2010).

To sum up, long-running heated debates concerning the effectiveness of direct versus indirect corrective feedback has been provoked, added to that the results of many studies has been varied and mixed. For instance, Jokar and Soyoof (2014), Salimi and Ahmadpour (2015) and Almasi and Tabrizi (2016) claimed that direct corrective feedback is more effective than indirect corrective feedback. On the other hand, Vinagre and Munoz (2011), Eslami (2014), Jamalinesari, et.al (2015) and Tan and Manochphinyo, (2017) alleged that indirect corrective feedback is more effective than direct corrective feedback. Nevertheless, Karim, and Nassaji, (2018), Van Beuningen, et al. (2012) and Vyatkina (2010) assumed that both direct and indirect corrective feedback are similar in their effectiveness in developing grammatical accuracy in writing. Such perplexing results sustained the need for new studies comparing the effectiveness of direct and indirect corrective feedback in reducing learners' grammatical errors in writing.

With this in mind, the current study focused mainly on the two key modes of corrective feedback namely, direct and indirect as they represent the two ends of the 
corrective feedback continuum, for providing a contribution to the burning issue of the superiority of one over the other. In addition, the study might provide a cut and dried answer regarding the potential effectiveness of the target modes as the available literature produced mixed and contradictory results (Abadikhah, \& Ashoori, 2012; Ferris, Helt, 2000; Kang \& Han, 2015; Sheen, 2007; Tan \& Manochphinyo, 2017).

\section{Purpose of the Study}

The principal aim of the present study was to investigate the effectiveness of direct versus indirect corrective feedback modes in developing grammatical accuracy in writing among the EFL majors at the Faculty of Education, Al-Azhar University. Thorough the analysis of a diagnostic test completed by (17) EFL majors at the Faculty of Education of Al-Azhar University, it was revealed that the candidates committed diverse frequent grammatical errors in terms of verb tense, subject verb agreement, sentence fragment, run-on sentence and comma splice, definite and indefinite articles and punctuation.

Thereupon, the study sought to answer the following key research questions:

1. What is the effectiveness of direct corrective feedback in developing the EFL majors' grammatical accuracy in writing?

2. What is the effectiveness of indirect corrective feedback in developing the EFL majors' grammatical accuracy in writing?

3. Which mode of corrective feedback (direct or indirect) is more effective in developing the EFL majors' grammatical accuracy in writing?

\section{Hypotheses of the Study}

To obtain pertinent answers for the research questions, the following hypotheses were proposed: 
1. There was no statistically significant difference at 0.05 level between the mean scores attained by the first experimental group students (direct corrective feedback) in their grammatical accuracy before and after the treatment.

2. There was no statistically significant difference at 0.05 level between the mean scores attained by the second experimental group students (indirect corrective feedback) in their grammatical accuracy before and after the treatment.

3. There was no statistically significant difference at 0.05 level between the mean scores attained by the first experimental group students (direct corrective feedback) and those attained by the second experimental group students (indirect corrective feedback) in their grammatical accuracy in the post writing test.

\section{Methods and Procedures}

\section{Design and Treatment Material}

The current study adopted the quasi-experimental design (The pretest-posttest equivalent group design). The first experimental group studied the suggested training program and received direct corrective feedback and the second experimental one studied the suggested training program and received indirect corrective feedback.

The treatment material of the present study was epitomized in a training program developed in the light of Kemp model due to its flexibility; as well as it is non-linear in its design and does not have specific starting or end points (Morrison, Ross, \& Kemp, 2004). The program consisted of six unites devoted for teaching six grammatical rules in a contextual writing environment. These topics were: verb tense, subject verb agreement, 
sentence fragment, run-on sentence, definite and indefinite articles and punctuation (see appendix 3 for scope and sequence of the program). The content validity of the program was assured via submitting it to three experts in the field of curriculum and instruction (EFL) who provided some constructive feedback ranging from linguistic, teaching strategy and in-class activities. All agreed on the idea that the main purpose was to teach these grammatical rules in a contextual writing environment. Such constructive feedback was thoroughly taken into consideration and helped the researchers in administering the program.

\section{Participants}

The study participants comprised fifty first-year EFL majors at the Faculty of Education, Al-Azhar University during the academic year (2016 / 2017 A.D.). They were randomly assigned into two experimental groups, using the SPSS formula "random distribution", with 25 participants in each. Consequently, as randomization ensures equivalence in the cognitive output, the groups were assumed to be equivalent to an adequate degree for ensuring the thoroughness of the results. Furthermore, the homogeneity of the groups was statistically assured via using an independent sample $t$-test before conducting the statistical analysis. The $t$-test result of the students' grammatical accuracy was insignificant, exactly 1.50 , indicating that both groups were homogeneous in their grammatical accuracy (see table 1).

Table 1:Independent Sample t-test (groups homogeneity in grammar).

\begin{tabular}{|c|c|c|c|c|c|c|c|}
\hline Variable & Group & Sample & Mean & $\begin{array}{c}\text { Std. } \\
\text { Deviation }\end{array}$ & $\begin{array}{c}\text { Std. Error } \\
\text { Mean }\end{array}$ & $t$ & $\begin{array}{c}\text { Sig. } \\
\text { (2tailed) }\end{array}$ \\
\hline & Ex1 & 25 & 34.08 & 25.72 & 5.14 & \multirow{2}{*}{1.50} & \\
\hline & Ex2 & 25 & 43.28 & 16.53 & 3.30 & & \\
\hline
\end{tabular}




\section{Instruments of the Study}

To accomplish the purpose of the current study, a writing test assessing the grammatical accuracy of the study participants was developed by the researchers. The initial form of the test was in the form of a booklet and comprised two tasks with two alternatives. It was submitted to 9 of the specialists in the field of TEFL education for test validity. The jury members were requested to judge the test in terms of task consistency, clarity, readability, cultural familiarity, and items sufficiency to measure the grammatical accuracy. They suggested that more alternatives should be added to the tasks to avoid task difficulty variable and give students the opportunity to select a topic that might attract their own interests and to be able to express their own ideas in a detailed manner using the target grammatical rules. In addition, they suggested also deleting the topic of hijab because it is controversial and distracting to students' attention. Furthermore, they modified certain words of the tasks to be easier. In this regard, the final form (see appendix 1) encompassed three alternatives and the student had to choose only one.

Added to that, for computing reliability, the writing performance of 15 students (not included in the final experiment), was systematically assessed and analyzed by two specialized raters in TEFL. The times of agreement and disagreement concerning the written product were calculated and statistically analyzed using Holisti's formula of calculating reliability (Holsti, 1969) as follows:

$$
{ }^{1} \mathrm{R}=\frac{2 \mathrm{M}}{\mathrm{N} 1+\mathrm{N} 2} \mathrm{R}=\frac{2890}{3096} \mathrm{R}=0.933
$$

1 - (M) is the total items agreed upon, (N1) is total items coder 1 selected and (N2) is total items coder 2 selected. 
The results of the analysis showed that the test reliability was 0.93 , which means that the test was highly reliable and ready to be administered to the study participants. Finally, for scoring the students' written product, an analytic scoring rubric consisting of five descriptors was developed by the researchers (see appendix 2). The students' performance ranged from excellent, very good, good, fair and unsatisfactory. The total score of the test was 96 marks.

The results of the analysis showed that the test reliability was 0.93 , which means that the test was highly reliable and ready to be administered to the study participants. Finally, for scoring the students' written product, an analytic scoring rubric consisting of five descriptors was developed by the researchers (see appendix 2). The students' performance ranged from excellent, very good, good, fair and unsatisfactory. The total score of the test was 96 marks.

\section{Administration Procedures}

The administration process lasted for 12 weeks during the second semester of the academic year (2016/2017). The class sessions were held three times a week and each session lasted for 90 minutes. The training program was incorporated into a competency-based syllabus aiming to promote the students' grammatical accuracy in writing. To fulfill such purpose, three key stages were pursued. In the first one, the pre-test was administered and students were then randomly assigned into two experimental groups (25 candidates in each). The instruction conditions were adjusted to be exactly the same for the two groups except for the mode utilized for the provision of the written feedback as one group received direct corrective feedback while the second received indirect one. 
In the second stage, the teaching sessions were delivered in the light of the following set procedures: initially, the writing lesson began with the instructor, one of the researchers, submitting an essay topic for the participants and briefly clarifying the topic and how to tackle the writing task in less than 20 minutes. Then, the students started writing the composition in a 70-minute class. The responses were collected every three sessions during the experimentation process an in the third session, the instructor handed the participants' their writings after providing the target mode of feedback accordingly and calculating the grammatical accuracy scores. Before returning the essays to the students, each marked essay was photocopied for thorough subsequent analyses. Finally, after each session, the researchers asked the participants to rewrite the essays again in the light of the feedback provided and bring them back the following session. In the next session, after collecting the fine-tuned pieces of writing, the instructor gave the participants another topic to think about and prepare themselves at home for the other next session. The same procedures were kept going for the rest of the administration process as twelve pieces of writings were collected for each candidate in this way.

In the last stage, each participant had to complete the posttest. Since the researchers aimed to use the same test questions of pre-test for the post-test, the participants did not receive any feedback on their pre-test writing and their pieces of writing were not given back to them. For both groups, the post-test was completed in the last session according to the specified estimated time.

\section{Results of the Study :}

The research questions of the study will be used as a guide to highlight the data analysis, the descriptive and inferential statistics and explanations of the yielded results. 


\section{The first question}

To answer the first research question, the subsequent hypothesis stating "There is no statistically significant difference at 0.05 level between the mean scores attained by the first experimental group learners (direct corrective feedback) in their grammatical accuracy before and after the treatment" was posed. Taking into account the nature of the hypothesis proposed, a paired sample $t$-test was utilized. Precisely, a comparison between the pre and posttest mean scores of the first experimental group was drawn to figure out the difference in the grammatical accuracy before and after the treatment. Table (2) displayed the results of the descriptive and the inferential statistical analyses:

Table 2:Paired Sample t-test (EX1 pre- post writing test).

\begin{tabular}{cccccccc}
\hline Group & Treatment & No. & Mean & $\begin{array}{c}\text { Std. } \\
\text { Deviation }\end{array}$ & $\begin{array}{c}\text { T- } \\
\text { Value }\end{array}$ & $\begin{array}{c}\text { Sig. } \\
\text { (2tailed) }\end{array}$ & $\begin{array}{c}\text { Cohen's } \\
d\end{array}$ \\
\hline \multirow{2}{*}{ EX1 } & Pre & 25 & 34.08 & 25.7 & 9.37 & 0.00 & \multirow{2}{*}{1.8} \\
\cline { 2 - 8 } & Post & 25 & 71.48 & 11.39 & & \\
\hline
\end{tabular}

The above results specified that there was a statistically significant difference between the mean scores attained by

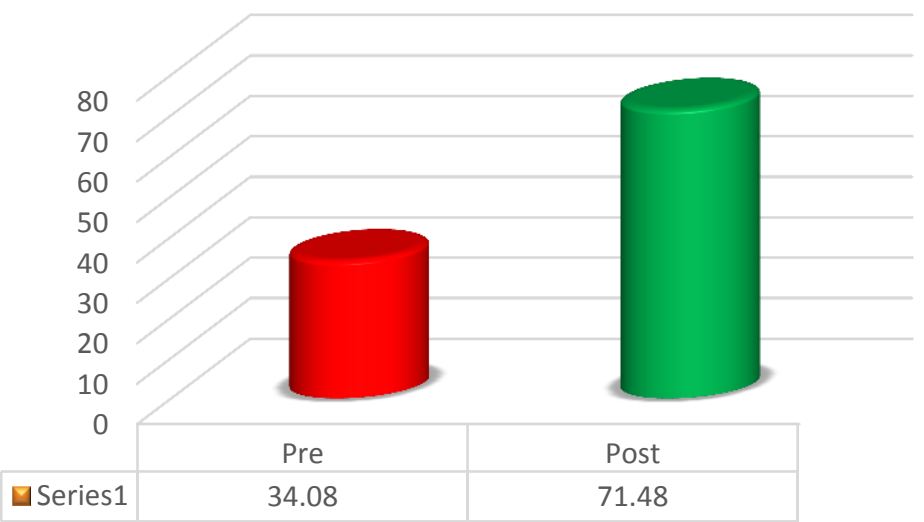

Figure 1. Experimental group one (writing pre-post test). the first experimental group learners (pre and post-test) in the grammatical accuracy in writing as measured by the 
writing test. Results of the $t$-test yielded (9.37) which is significant (sig. $=0.002$ tailed $=\mathrm{P}<0.05$ ). Over and above, the figure (1) below delineated the difference in the grammatical accuracy in writing of the first experimental group before and after the treatment.

The figure (1) above showed that there was an obvious difference between the mean scores of the first experimental group learners in the pre and post writing test. Subsequently, the first null hypothesis was rejected and the alternative hypothesis was accepted signifying that there was a statistically significant difference at 0.05 level between the mean scores attained by the first experimental group learners (direct corrective feedback) in their grammatical accuracy before and after the treatment.

Additionally, to validate the results obtained, the effect size (how much variance in grammatical accuracy in writing was a result of the direct corrective feedback) was computed using the cohen's $d$ formula, which yielded $(d=$ 1.8) identifying that $96.40 \%$ of the improvement in the grammatical accuracy of the target group may be attributed to the treatment. Hence, in the light of the results drawn above, the direct mode of corrective feedback had a considerable effectiveness in developing the grammatical accuracy in writing among the first-year EFL majors at the Faculty of Education, Al-Azhar University.

\section{The second question}

To answer the second research question the subsequent hypothesis expressing "There is no statistically significant difference at 0.05 level between the mean scores attained by the second experimental group learners (indirect corrective feedback) in their grammatical accuracy before and after the treatment" was anticipated. Due to the nature of the hypothesis displayed, a paired sample $t$-test was employed. Precisely, a comparison between the pre and 
posttests mean scores of the second experimental group was made to figure out the difference in their grammatical accuracy before and after the treatment. Table (3) disclosed the results of the statistical analysis:

Table 3: Paired Sample t-test (EX2 pre- post writing test).

\begin{tabular}{cccccccc}
\hline Group & $\begin{array}{c}\text { Treatme } \\
\text { nt }\end{array}$ & No. & Mean & $\begin{array}{c}\text { Std. } \\
\text { Deviation }\end{array}$ & T-Value & $\begin{array}{c}\text { Sig. } \\
(2 \text { tailed) }\end{array}$ & Cohen's $d$ \\
\hline EX2 & Pre & $\mathbf{2 5}$ & $\mathbf{4 3 . 2 8}$ & $\mathbf{1 6 . 5 3}$ & 7.48 & $\mathbf{0 . 0 0}$ & 1.75 \\
\cline { 2 - 6 } & Post & $\mathbf{2 5}$ & $\mathbf{6 6 . 9 6}$ & $\mathbf{9 . 4 7}$ & & \\
\hline
\end{tabular}

The results shown above quantified that there was a statistically significant difference between the mean scores attained by the second experimental group learners (pre and posttest) in the grammatical accuracy as measured by the writing test. Results of the $t$-test yielded (7.48) which is significant (sig. $=0.002$ tailed $=\mathrm{P}<0.05$ ). Above and beyond, the figure (2) below outlined the difference in the grammatical accuracy of the second experimental group before and after the treatment.

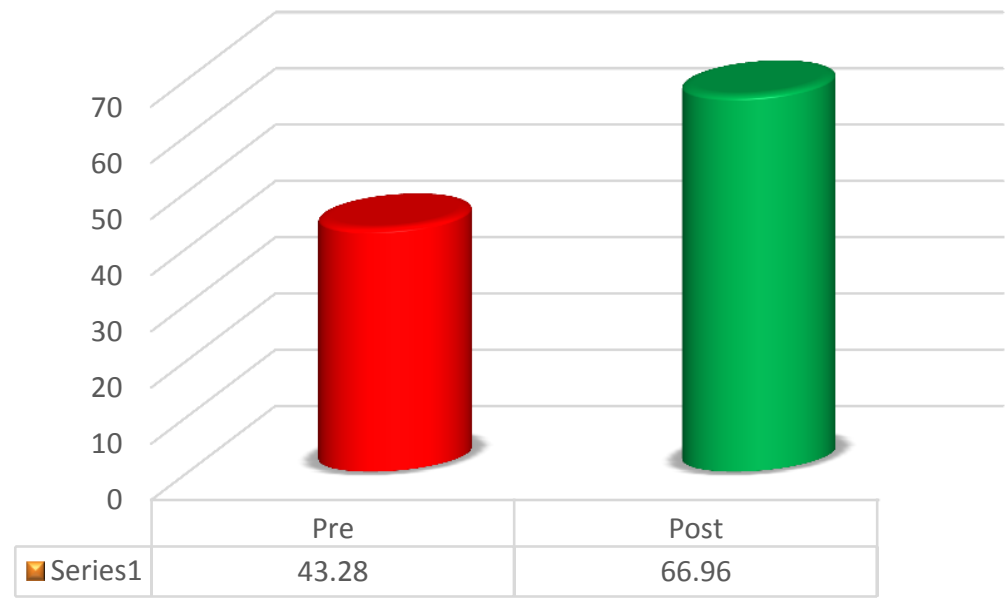

Figure 2. Experimental group two (writing pre-post test).

The above figure (2) showed that there was a recognizable difference between the mean scores of the second experimental group learners in the pre and post writing 
tests. Therefore, the second null hypothesis was rejected and the alternative hypothesis was accepted verifying that there was a statistically significant difference at 0.05 level between the mean scores attained by the second experimental group learners (indirect corrective feedback) in their grammatical accuracy before and after the treatment.

Furthermore, to authenticate the results of the statistical analysis, the effect size (how much variance in grammatical accuracy was a result of the indirect corrective feedback) was computed using the cohen's $d$ formula, which yielded $(d=1.75)$ determining that $95.5 \%$ of the improvement in the grammatical accuracy of the target group may be attributed to the treatment. Accordingly, the results drawn above manifested the effectiveness of the indirect corrective feedback mode in developing the grammatical accuracy in writing among the first-year EFL majors at the Faculty of Education, Al-Azhar University.

\section{The third question}

To answer the third research question the subsequent hypothesis was processed to compare the effectiveness of the direct versus the indirect mode of corrective feedback claiming "There is no statistically significant difference at 0.05 level between the mean scores attained by the first experimental group students (direct corrective feedback) and those attained by the second experimental group students (indirect corrective feedback) in the grammatical accuracy in the post writing test". As the two groups were verified to be homogeneous; an independent sample $t$-test was implemented. Precisely, a comparison was performed between the posttests of the first and second experimental groups mean scores to reveal the difference in the grammatical accuracy before and after the treatment. Table (4) demonstrated the results of the statistical analysis: 
Table 4:Independent Sample t-test (EX1\&EX2 post writing test).

\begin{tabular}{cccccc}
\hline Group & No. & Mean & $\begin{array}{c}\text { Std. } \\
\text { Deviation }\end{array}$ & T-Value & $\begin{array}{c}\text { Sig. } \\
\text { (2tailed) }\end{array}$ \\
\hline Ex1 & 25 & $\mathbf{7 1 . 4 8}$ & $\mathbf{1 1 . 3 9}$ & 1.52 & 0.13 \\
\hline Ex2 & 25 & $\mathbf{6 6 . 9 6}$ & $\mathbf{9 . 4 7}$ & & 0 \\
\hline
\end{tabular}

The results displayed above underscored that there was no statistically significant difference at 0.5 level between the mean scores attained by the first and the second experimental groups (posttest) in the grammatical accuracy as measured by the writing test. Results of the $t$-test yielded (1.52) which was not significant (sig. $=0.1342$ tailed $=\mathrm{P}>$ 0.05 ). Other than that, the figure (4) below delineated the mean difference in the grammatical accuracy of the first and second experimental groups in the posttest.

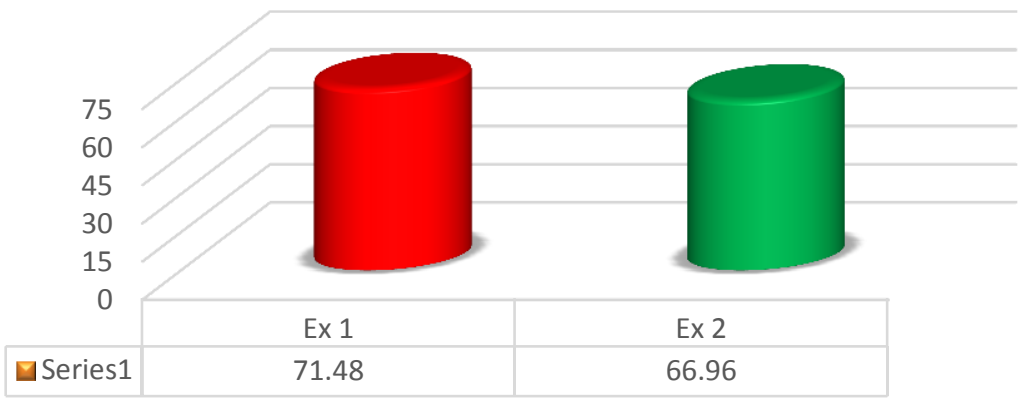

Figure 3. Experimental groups one and two (writing post-test).

The figure (4) above disclosed that there was no evident difference between the mean scores of the first and second experimental groups in the posttest. Accordingly, the third null hypothesis was accepted demonstrating that there was no statistically significant difference at 0.05 level between the mean scores attained by the first experimental group students (direct corrective feedback) and those attained by 
the second experimental group students (indirect corrective feedback) in the grammatical accuracy in the post writing test. Respectively, the results obtained above indicated that both direct and indirect corrective feedback are effective in developing grammatical accuracy in writing and both of them have roughly the similar effectiveness.

To substantiate the results of the statistical analysis, indicating that there was no statistically significant difference between the mean scores attained by the first and second experimental group learners (direct versus indirect corrective feedback) in their grammatical accuracy before and after the treatment, a comparison was held between the sub-grammatical aspects targeted by the present study. In other words, an independent sample $t$-test was used to calculate the significance of the means difference among the grammatical aspects after the experimentation (posttest). Table (5) displayed the results of the statistical analysis:

Table 5: Independent Sample t-test (EX1\&EX2 post subgrammatical aspects test).

\begin{tabular}{|c|c|c|c|c|c|c|}
\hline $\begin{array}{l}\text { Grammatical } \\
\text { aspect }\end{array}$ & Group & No. & Mean & $\begin{array}{c}\text { Std. } \\
\text { Deviation }\end{array}$ & T-value & $\begin{array}{c}\text { Sig. } \\
\text { (2tailed) }\end{array}$ \\
\hline \multirow{2}{*}{ Verb tense } & Ex1 & 25 & 11.56 & 2.93 & \multirow{2}{*}{1.72} & \multirow{2}{*}{0.09} \\
\hline & Ex2 & 25 & 6.96 & 3.58 & & \\
\hline \multirow{2}{*}{$\begin{array}{c}\text { Subject verb } \\
\text { agreement }\end{array}$} & Ex1 & 25 & 12.28 & 2.79 & \multirow{2}{*}{0.71} & \multirow{2}{*}{0.47} \\
\hline & Ex2 & 25 & 12.72 & 2.74 & & \\
\hline \multirow{2}{*}{ Run-on Sentence } & Ex1 & 25 & 14.84 & 2.09 & \multirow{2}{*}{0.58} & \multirow{2}{*}{0.56} \\
\hline & Ex2 & 25 & 14.48 & 2.25 & & \\
\hline \multirow{2}{*}{$\begin{array}{c}\text { Definite \& indefinite } \\
\text { articles }\end{array}$} & Ex1 & 25 & 13.88 & 1.85 & \multirow{2}{*}{1.78} & \multirow{2}{*}{0.08} \\
\hline & Ex2 & 25 & 12.80 & 2.39 & & \\
\hline \multirow{2}{*}{ Sentence fragment } & Ex1 & 25 & 12.52 & 3.41 & \multirow{2}{*}{1.37} & \multirow{2}{*}{0.17} \\
\hline & Ex2 & 25 & 11.16 & 3.59 & & \\
\hline \multirow{2}{*}{ Punctuation } & Ex1 & 25 & 5.40 & 4.16 & \multirow{2}{*}{0.37} & \multirow{2}{*}{0.71} \\
\hline & Ex2 & 25 & 5.84 & 4.15 & & \\
\hline
\end{tabular}

The results shown above assured that there was no statistically significant difference at 0.5 level between the mean scores attained by the first and the second experimental groups (posttest) in the sub-grammatical 
aspects as measured by the writing test. Results of the $t$-test respectively yielded $(1.72,0.71,0.58,1.78,1.37,0.37)$ which were not significant. Over and above, the figure (4) below delineated the mean difference in the subgrammatical aspects of the first and second experimental groups in the posttest.

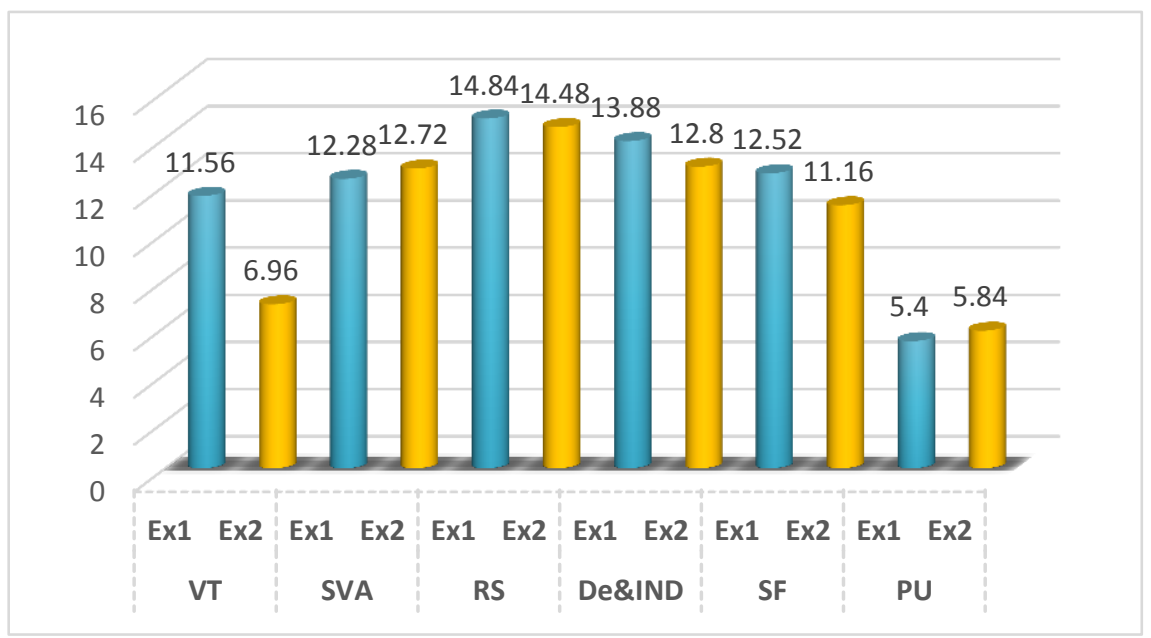

Figure 4. Experimental groups one and two (sub-grammatical aspects post-test).

The figure (4) above unveiled that there was no evident difference between the mean scores of the first and the second experimental groups in the sub-grammatical items. Consequently, both direct and indirect corrective feedback modes have roughly analogous significance in developing the sub grammatical aspects of the study participants.

\section{Discussion}

The results of the statistical analysis underscored that both direct and indirect corrective feedback had advantageous effectiveness in developing the grammatical accuracy in writing of the study participates.

To start with, the findings of the study revealed the effectiveness of direct corrective feedback. Direct provision of error feedback was less time-consuming for 
teachers and less frustrating for the students, which means that the direct mode of corrective feedback was a handy option for teachers and students. A plausible interpretation of the generated result is that direct corrective feedback may reduce the confusion that may be experienced by the students when they fail to understand or remember the meaning of the underline or the circle provided by the instructor/s. More than that, direct corrective feedback provided the students with sufficient information about the grammatical errors made while writing. Another possible interpretation of the result is that direct corrective feedback was very time-saving as it provided the learner with the correct linguistic structure above or beside the linguistic error. As a consequence, the students were able to figure out the differences between the two forms, the erroneous and the correct one, which might polish the blur image in the mind of the learner in relation to the usage of the target grammatical aspect (Sarvestani, \& Pishkar, 2015; Sun, 2013).

Furthermore, as the learners' time was saved, they did not copy and paste the right form instead of the erroneous one, but they might revisit the rule governing the errors made which, in turn, enabled them to apply thoroughly the same rules in the encountered similar situations. Thus, acquiring the rules and functionalizing them in a meaningful context qualify the students to master the target grammatical rule and mature their grammatical accuracy in writing. Moreover, getting the correct form encouraged the learner to avoid making the same errors and had deeper understanding of the correct structures. Consequently, learners were supported to become more self-directed, which in turn played a significant role in assisting them mastering the target grammatical aspect (Baleghizadeh, \& Dadashi, 2011). 
The results attained concerning the effectiveness of direct corrective feedback are in line with those of some studies (Ferris, \& Helt, 2000; Van Beuningen, et al. 2012; Jokar \& Soyoof, 2014; Salimi \& Ahmadpour, 2015; and Almasi and Tabrizi, 2016) which reported that the direct corrective feedback on errors help the learners improve accuracy in their writing. The results however are different from some others, which reported that the corrective feedback on grammatical errors could not assist the learners to improve accuracy in their writing (Truscott\& Hsu, 2008) as they depend on a small sample consisted of 21 students in the ESL context. The results of the experimentation revealed a small effectiveness of the feedback, but such effectiveness was not significant; consequently, they adopted the opposite view of the corrective feedback effectiveness.

Likewise, the outcomes of the statistical analysis testified the useful effect of the indirect corrective feedback mode on maturing the grammatical accuracy among the EFL learners' writings. It was approved that the indirect corrective feedback is an operative educational tool that can be adopted to achieve considerable outcomes in the field of grammar teaching.

A reasonable interpretation of the yielded results is that the indirect corrective feedback engaged the students in guided learning and problem solving, which in turn maximized their efforts to acquire the targeted grammatical aspects. The feedback in the form of underlining or circling the errors made by the students inquired them to search for the reasons for such errors and the possible acceptable corrections. The problem-solving atmosphere experienced by the students accompanied by the guided learning practices provided by the instructor led to the fruitful results attained. The current result agreed with that of (Eslami, 2014; Ferris, \& Roberts, 2001; Ghandi, \& 
Maghsoudi, 2014 \& Hosseiny, 2014; Tan \& Manochphinyo, 2017).

Another conceivable explanation of the result attained is that indirect error correction induced the learners to become more self-activated and responsible for their learning process. The learners' roles according to the indirect mode of corrective feedback changed to some extent, as they were responsible for understanding, correcting and applying the acquired target rules in similar contexts without errors. Thereby, the indirect mode of corrective back is working in the light of the learner autonomy theory proposed by Holec (1980) (Sivaji, 2012).

Further sensible interpretation of the result obtained is that the indirect mode of corrective feedback encouraged the students to think and search for the target grammatical issue in the books and corpora to correct the marked errors and acquire the grammatical rules behind. Moreover, as the students were mature enough and the technological means make the learning and the searching process easier, they encountered no difficulties in getting the correct answers for their questions under the researcher supervision $(\mathrm{Xu}, \&$ Huang, 2014).

These finding echoes other research and studies that addressed the same issues (Ferris \& Helt 2000; Jamalinesari, 2015; Tan \& Manochphinyo, 2017). Those studies and many others reported that the indirect corrective feedback helps the learners improve grammatical accuracy in their writing. The results however are inconsistent with other studies, which asserted that the corrective feedback on error cannot help the learners improve accuracy in their writing (Truscott\& Hsu, 2008) as such studies adopted the opposite view of the corrective feedback effectiveness due to the insignificance of the treatment. 
Correspondingly, the obtained results attested that there were no statistically significant differences between the direct and indirect modes of corrective feedback concerning their advantageous effects in developing the study participants' grammatical accuracy in writing. It was realized that both of them have similar or equal effect in developing the participants' grammatical accuracy in writing.

A rational explanation for the obtained results can be the fact that both groups, irrespective of the mode of feedback, similarly received systematic corrective feedback, thus, both groups rather equally improved in grammatical accuracy in writing. Additionally, both groups received the same content via the same instructor in the same allocated time, which reflected in the equality of both groups concerning the results (Saadi, \& Saadat, 2015).

A sensible acceptable interpretation of such result is that the noticing hypothesis is the main guided theory of the corrective feedback in general. Thus, both direct and indirect corrective feedback are two main modes under the umbrella construct "feedback", which means that providing corrective feedback push the students towards the linguistic problems they are struggling with. In other words, direct or indirect corrective feedback prompts the students to try to modify their developing interlanguage system in line with the feedbacks provided (Schmidt, 1990, 1994).

These findings are in harmony with a considerable amount of research issuing the same research constructs (Ferris \& Helt, 2000; Ferris \& Roberts, 2001; Nakazawa, 2006; Vyatkina, 2010; Van Beuningen, et al., 2012). Those studies and many others assured that there is no significant difference between direct versus indirect modes of corrective feedback in developing linguistic aspects. The results however are not consistent with other studies, which 
reported that direct corrective feedback is more fruitful than indirect corrective feedback (Almasi \& Tabrizi, 2016; Salimi \& Ahmadpour, 2015; Shirazi \& Shekarabi, 2013; Suh, 2014); or those studies which showed that indirect corrective has productive effects than direct corrective feedback (Baleghizadeh \& Dadashi, 2011; Eslami, 2014; Ghandi, \& Maghsoudi, 2014, Hosseiny 2014).

\section{Conclusion :}

Bearing in mind that the study is limited in terms of number and context; and on the basis of the results obtained, it can be concluded that functionalizing the target grammatical aspects in a productive context, namely, writing or speaking, is a superlative way for attaining the meaningful learning and accomplishing the teaching learning process objectives. In addition, corrective feedback, with its two modes, is a thoughtful method of managing the potentially burdensome workload of giving grammar feedback. Moreover, the results of the study revealed no superiority for one mode over the other. This means the direct method, though claimed by many to be less fruitful over time, may be a more handy option for teachers for onsite error correction. On the other hand, applying indirect methods of error correction will necessarily call for sufficient linguistic knowledge possessed by students to self-correct errors and also getting used to self-edit their own texts. Therefore, using both methods is recommended for the onsite and offsite correction and for the different levels of students.

Finally, and based on the results obtained, future research is recommended to explore how corrective feedback affects students' satisfaction with classroom content and grades. Additionally, a longitudinal study may also be developed to see if the different methods of corrective feedback (direct, indirect or blended) have long-term effects on writing or grammar improvement in different writing contexts. By tailoring the amount and type of feedback 
given to students, and by involving students directly in that decision, these methods can be one option to provide the more finely-tuned approach to written corrective feedback that may benefit both students and teachers.

\section{References}

Abadikhah, S., \& Ashoori, A. (2012). The effect of written corrective feedback on EFL learners' performance after collaborative output.Journal of Language Teaching and Research, 3(1), 118-125.

Abbasian1, G., \& Parsarad, P. (2013). Differential effectiveness of corrective feedback techniques on the development of advanced Iranian EFL learners' grammar ability. ELT Voices India International Journal, 3(6), 62-70.

Almasi, E., \& Tabrizi, A. R. N. (2016). The effects of direct vs. indirect corrective feedback on Iranian EFL learners' writing accuracy. Journal of Applied Linguistics and Language Research, 3(1), 74-85.

Amara, N. (2015). Errors correction in foreign language teaching. The Online Journal of New Horizons in Education, 5(3), 58-68.

Baleghizadeh, S., \& Dadashi, M. (2011). The effect of direct and indirect corrective feedback on students' spelling errors. Profile Issues in Teachers Professional Development, 13(1), 129-137.

Bangert-Drowns, R. L., Kulik, C. C., Kulik, J. A., \& Morgan, M. T. (1991). The instructional effect of feedback in test-like events. Review of Educational Research, 61(2), 213-238.

Bitchener, J. (2008). Evidence in support of written corrective feedback. Journal of Second Language Writing, 17(2), 102118.

Bitchener, J., \& Knoch, U. (2009). The relative effectiveness of different types of direct written corrective feedback. System, 37(1), 322-329.

Cawley, V. D. (2017). Contextualized Grammar Instruction: A Case Study of Master's Students' Writing Development (Doctoral dissertation). Judson University. 
Celce-Murcia, M. (2002). Why it makes sense to teach grammar in context and through discourse. In E. Hinkel, \& S. Fotos, New perspectives on grammar teaching in second language classrooms (pp. 119-134). Erlbaum.

Chomsky, N. (1965). Aspects of the theory of syntax. MIT Press.

Chu, R. (2011). Effects of teacher's corrective feedback on accuracy in the oral English of English-Majors College Students. Theory and Practice in Language Studies, 1(5), 454459.

Diab, N. M. (2015). Effectiveness of written corrective feedback: Does tvpe of error and type of correction matter?. Assessing Writing, 24, 16-34.

Diab. N. M. (2016). A comparison of peer, teacher and selffeedback on the reduction of language errors in student essays. System, 57, 55-65.

Ellis, R. (2009). A typology of written corrective feedback types. ELT Journal, 63(2), 97-107.

Eslami, E. (2014). The effects of direct and indirect corrective feedback techniques on EFL students' writing. ProcediaSocial and Behavioral Sciences, 98, 445-452.

Fareed, M., Ashraf, A., \& Bilal, M. (2016). ESL learners' writing skills: Problems, factors and suggestions. Journal of Education and Social Sciences, 4(2), 81-92.

Ferris, D. R., \& Helt, M. (2000). Was Truscott right? New evidence on the effects of error correction in L2 writing classes. $A A A L$ Conference, Vancouver, BC.UK.

ferris, D. R., \& Roberts, B. (2001). Error feedback in L2 writing classes: How explicit does it need to be? Journal of Second Language Writing, 10(3), 161-184.

Ghandi, M., \& Maghsoudi, M. (2014). The effect of direct and indirect corrective feedback on Iranian EFL learners' spelling errors. English Language Teaching, 7(8), 53.

Han, J., \& Hiver, P. (2018). Genre-based L2 writing instruction and writing-specific psychological factors: The dynamics of change. Journal of Second Language Writing, 40, 44-59.

Hartono, D. A. (2016). The debate on written corrective feedback: its importance and implication for academic writing 
instruction in EFL settings. The 61 TEFLIN International Conference. UNS Solo. Indonesia.

Holec, H. (1980). Learner trainina: meetina needs in self-directed learning. Foreign language learning: Meeting individual needs. Pergamon.

Holsti, O. R. (1969). Content analysis for the social sciences and humanities. Reading. MA: Addison-Wesley (content analysis).

Hosseiny, M. (2014). The role of direct and indirect written corrective feedback in improving Iranian EFL students' writing skill. Procedia - Social and Behavioral Sciences, 98, 668-674.

Iswandari, D. C., Prayogo, J. A., \& Cahyono, B. Y. (2017). Effect of environmental problem-based learning on the Indonesian EFL students' environment-related vocabulary mastery and writing ability. Theory and Practice in Language Studies, 7(8), 608-616.

Jamalinesari, A., Rahimi, F., Gowharv, H., \& Azizifar, A. (2015). The effects of teacher-written direct vs. indirect feedback on students' writing.Procedia-Social and Behavioral Sciences, 192(1), 166-123.

James, C. (2013). Errors in language learning and use: Exploring error analysis. Routledge.

Jokar, M., \& Soyoof, A. (2014). The influence of written corrective feedback on two Iranian learners' grammatical accuracy. Procedia - Social and Behavioral Sciences, 98, 799805.

Kang, E., \& Han, Z. (2015). The efficacy of written corrective feedback in improving L2 written accuracy: A MetaAnalysis. The Modern Language Journal, 99(1), 1-18.

Karim, K., \& Nassaji, H. (2018). The revision and transfer effects of direct and indirect comprehensive corrective feedback on ESL students' writing. Language Teaching Research, 1362168818802469.

Krashen, S., Dulay, H. C., \& Burt, M. K. (1982). Language two. Oxford University Press.

$\mathrm{Li}, \mathrm{S}$. (2013). The interactions between the effects of implicit and explicit feedback and individual differences in language 
analytic ability and working memory. Modern Language Journal, 97, 634-654.

Liao, H. C. (2016). Enhancing the grammatical accuracv of EFL writing by using an AWE-assisted process approach. System, 62, 77-92.

Likai, M. (2015). Teaching Writing through Communicative Approach in Military English.Journal of Education and Practice, 6(20), 102-107.

Mahmoudi, A. (2017). Effect of planning on Iranian intermediate EFL learners' mastery of writing skill. Theory and Practice in Language Studies, 7(3), 219-226.

Morrison, G. R., Ross, S. M., \& Kemp, I. E. (2004). Designing effective instruction (4th ed.). USA: John Wiley \& Sons.

Myhill, D., \& Watson, A. (2014). The role of grammar in the writing curriculum: A review of the literature. Child Language Teaching and Therapy, 30(1), 41-62.

Nakazawa, K. (2006). Efficacy and effects of various types of teacher feedback on student writing in Japanese (Ph.D. Dissertation), Purdue University.

Özdemir, E., \& Avdin, S. (2015). The effects of blogging on EFL writing achievement. Procedia-social and behavioral sciences, 199(1), 372-380.

Phuket, P. R. N., \& Othman, N. B. (2015). Understanding EFL Students' Errors in Writing. Journal of Education and Practice, 6(32), 99-106.

Saadi, Z. K., \& Saadat, M. (2015). EFL learners' writing accuracy: effects of direct and metalinguistic electronic feedback. Theory and Practice in Language Studies, 5(10), 2053-2063.

Salimi, A., \& Ahmadpour, M. (2015). The effect of direct vs. indirect written corrective feedback on 12 learners' written accuracy in EFL context. International Journal of English Language and Literature Studies, 4(1), 10-19.

Sarvestani, M. S., \& Pishkar, K. (2015). The effect of written corrective feedback on writing accuracy of intermediate learners. Theory and Practice in Language Studies, 5(10), 2046. 
Seiffedin, A. H., \& El-Sakka, S. M. F. (2017). The impact of directindirect corrective e-feedback on EFL students' writing accuracy. Theory and Practice in Language Studies, 7(3), 166175.

Sermsook, K., Liamnimitr, I., \& Pochakorn, R. (2017). The Impact of Teacher Corrective Feedback on EFL Student Writers' Grammatical Improvement. English Language Teaching, 10(10), 43-49.

Sheen, Y. (2007). The effect of focused written corrective feedback and language aptitude on ESL learners' acquisition of articles. TESOL Quarterly 41, 255-283.

Sheen, Y. (2010). Differential effects of oral and written corrective feedback in the ESL classroom. Studies in Second Language Acquisition, 32, 203-234.

Shepherd, R. P., O’Meara, K. D., \& Snyder, S. E. (2016). Grammar agreements: Crafting a more finely tuned approach to corrective feedback. Journal of Response to Writing, 2(1), 4357.

Shintani, N., \& Aubrey, S. (2016). The effectiveness of synchronous and asynchronous written corrective feedback on grammatical accuracy in a computer-mediated environment. The Modern Language Journal,100(1), 296319.

Shirazi, M., \& Shekarabi, Z. (2013). The role of written corrective feedback in enhancing the linguistic accuracy of Iranian Japanese learners' writing. Iranian Journal of Language Teaching Research, 2(1), 99-118.

Singh, C. K. S., Singh, A. K. J., Razak, N. Q. A., \& Ravinthar, T. (2017). Grammar Errors Made by ESL Tertiary Students in Writing. English Language Teaching, 10(5), 16-27.

Sivaji, K. (2012). The effect of direct and indirect error correction feedback on the grammatical accuracy of ESL writing of undergraduates. Journal of Humanities \& Social Sciences, 8(7), 78-94.

Suh, B. R. (2014). The effectiveness of direct and indirect coded written feedback in English as a foreign language. Language Research, 50(3), 795-814. 
Sun, S. (2013). Written corrective feedback: Effects of focused and unfocused grammar correction on the case acquisition in L2 German (Ph. D. Dissertation, University of Kansas).

Tan, K. E., \& Manochphinyo, A. (2017). Improving Grammatical Accuracv in Thai Learners' Writing: Comparing Direct and Indirect Written Corrective Feedback.Journal of Asia TEFL, 14(3), 430.

Truscott, J. and Hsu A. Y. (2008). Error correction, revision, and learning. Journal of Second Language Writing, 17, 292-305.

Van Beuningen, C. G., De Jong, N. H., \& Kuiken, F. (2012). Evidence on the effectiveness of comprehensive error correction in second language writing. Language Learning, 62(1), 1-41.

Vinagre, M., \& Munoz, B. (2011). Computer-mediated corrective feedback and language accuracy in tele-collaborative exchanges. Language Learning \& Technology, 15(1), 72-103.

Vyatkina, N. (2010). The effectiveness of written corrective feedback in teaching beginning German. Foreign Language Annals, 43(4), 671-689.

$\mathrm{Xu}$, L., \& Huang, Y. Y. (2014). Corpus-based studv on corrective feedback. Iournal of Chongqing University of Technology (Social Science), 2, 19-35.

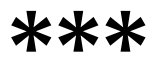

